\title{
A PERCEPÇÃO DE PROFISSIONAIS DA SAÚDE DE UM HOSPITAL SOBRE A VIOLÊNCIA CONTRA AS MULHERES
}

\author{
Letícia Becker VIEIRA a \\ Stela M aris de M ello PAD OIN ${ }^{b}$ \\ M aria Celeste LANDERDAHLC
}

\section{RESUMO}

Estudo qualitativo que objetivou conhecer percepções de profissionais de saúde acerca da assistência às mulheres em situação de violência. 0 cenário foi um hospital de ensino no sul do Brasil. Os sujeitos da pesquisa foram 12 profissionais de saúde do Centro Obstétrico e Pronto Socorro. A coleta dos dados realizou-se em abril/ maio de 2008, a partir de vinheta e entrevista semi-estruturada. As informações foram organizadas e estruturadas por meio da análise temática. D os resultados emergiram duas categorias: o diálogo como instrumento facilitador para a identificação da violência e seus encaminhamentos, ea complexidade do fenômeno esuas implicações na assistência. A ponta-se a necessidade de criação de espaços de responsabilização dos órgãos for madores e ser viços de saúde na formação de equipe multiprofissional que discuta e implemente a política de atendimento às mulheres em situação de violência.

D escritores: Violência contra a mulher. Saúde da mulher. A ssistência à saúde.

\section{RESUMEN}

E studio cualitativo que tuvo por objetivo conocer las percepciones de profesionales de salud acerca de la asistencia a las mujeres en situaciones de violencia. E l escenario fueun hospital de enseñanza en el sur de B rasil. L os sujetos dela investigación fueron 12 profesionales de salud del Centro 0 bstétrico y $\mathrm{H}$ ospital de urgencias. L a recolección de los datos se realizó en abril/ mayo de 2008, a partir de viñeta y entrevista semiestructurada. L as informaciones fueron organizadas y estructuradas por medio del análisis temático. D e los resultados emergieron dos categorías: el diálogo como instrumento facilitador para la identificación de la violencia y sus encaminamientos las mujeres y la complexidad del fenómeno y sus implicaciones en la asistencia. Se evidencia la necesidad de creación de espacios de responsabilidad de los órganos formadores y servicios de salud en la formación del equipo multiprofesional que discuta e implemente la política de atención a las mujeres en situación de violencia.

Descriptores: Viol encia contra la mujer. Salud de la mujer. Prestación de atención de salud. Titulo: L a percepción de profesionales de salud de un hospital sobre la violencia contra la mujer.

\section{ABST RACT}

This qualitative study aimed at finding out the perceptions of health professionals about the assistance to w omen living in a violent situation. T hescenery was a teaching hospital of souther $\mathrm{B}$ razil. Theparticipants w ere 12 health professional sfrom the obstetric and emergency units. T he data were collected by semi structured interviews started by a short story in A pril to $M$ ay of 2008. The information was organized and categorized and subject to thematic analysis. The results show ed two categories: the dialogue as a facilitator instrument to identify the violence and their referrals and the complexity of the phenomena and their implications to the assistance. We pointed out the necessity of to create spaces of the responsibility of agencies devoted to training human resources in health and health services. It is in order to for m multiprofessi onal team that discuss and implements the policy care to women living in a violent situation.

D escriptors: Violence against w omen. Women's health. D elivery of health care

$T$ itle: The perceptions of the health professionals at a hospital about the violence against women.

\footnotetext{
${ }^{a}$ E nfer meira, M estranda do Programa de Pós-G raduação em Enfermagem da U niversidade F ederal de Santa M aria (U F SM ), Bolsista da Coordenação de A perfeiçoamento de Pessoal de Nível Superior (CAPES), Vice-líder do Núcleo de Estudos sobre M ulheres, Gênero e Políticas Públicas do D epartamento de Enfermagem da U FSM, Santa M aria, Rio Grande do Sul, Brasil.

${ }^{b}$ D outora em Enfer magem, Professora A djunta da U F SM, Líder do grupo de pesquisa Cuidado à Saúde das Pessoas, Famílias e Sociedade da U F SM , Santa M aria, Rio G rande do Sul, Brasil

c M estre em Enfermagem, Professora Adjunta da UFSM, Líder do Núcleo de Estudos sobre M ulheres, Gênero e Políticas Públicas do D epartamento de Enfermagem da U F SM, Santa M aria, Rio Grande do Sul, Brasil.
} 


\section{INT RODUÇÃO}

A Convenção Interamericana para Prevenir, Punir e E rradicar a V iolência contra a M ulher definiu violência contra as mulheres como todo ato baseado no gênero, que cause morte, dano ou sofrimento físico, sexual ou psicológico ao segmento feminino, situação que viola seus dir eitos humanos e fere sua cidadania(1).

No Brasil, denúncias de violência contra as mulheres começaram a partir da segunda metade do século XX. A té então, era mencionada como um evento restrito ao âmbito privado, sendo exercida nos lares, sem a interven ção de terceiros. $G$ anhou notoriedade ao ser denunciada pelo M ovimento Feminista, o qual se configurou como um importante impulsionador para discussões e conquistas de iniciativas oficiais ao enfrentamento da violência.

N esse sentido, o E stado brasileiro, na tentativa de alinhar apelos e recomendações de conferências e convenções inter nacionais elaborou, em 2004, a Política Nacional de A tenção Integral à Saúde da M ulher, que incorporou em suas ações prioritárias a promoção da atenção a mulheres e adolescentes em situação de violência ${ }^{(2)}$. Evidencia-se assim, o reconhecimento do problema como uma questão de saúde pública.

N esta perspectiva, a violência contra as muIheres está associada a um maior risco para diversos ag ravos à sua saúde física e mental, implicando em aumento de demanda aos serviços de saúde ${ }^{(3)}$, cenário eleito por muitas mulheres na busca por ajuda. Na maioria das vezes o setor de emergência é a porta de entrada, e o único contato da muIher em situação de violência com o sistema de saú$d e^{(4)}$.

No entanto, há um desconhecimento por parte dos profissionais sobre o fenômeno da violência e seus diferentes matizes, prejudicando dessa maneira, a assistência oferecida às mulheres que vivenciam essa problemática. F reqüentemente o profissional não identifica a situação de violência, e quando o faz não se sente preparado para dar a solução ou o encaminhamento adequado(5).

Observa-se que o modelo de atenção às muIheres em situação de violência opera na lógica da racionalidade e reducionismo, reforçando o modelo biomédico na assistência realizada pelos profissionais de saúde( ${ }^{(6)}$. Compreende-se, assim, ser imprescindível que os serviços assumam uma postu- ra de responsabilização, implementando uma estrutura de atendimento voltado à identificação e acompanhamento terapêutico das situações de violência ${ }^{(7)}$.

T ais reflexões conduziram o presente estudo, o qual teve como questão nor teadora: como os profissionais de saúde identificam e encaminham a situação de violência? E, como objetivo: conhecer as percepções de profissionais de saúde que atuam no centro obstétrico e pronto socorro adulto de um hospital de ensino, acerca da assistência às mulheres em situação de violência.

\section{TRAJET ÓRIA}

E studo qualitativo, o qual teve como cenário um hospital de ensino do interior do Rio G rande do Sul, no Brasil. 0 projeto obteve aprovação do Comitê de É tica em Pesquisa da U niversidade Federal de Santa M aria (UFSM), sob parecer no 0020.0.243.000-08. Os sujeitos foram 12 profissionais de duas equipes de saúde, que atuam nas U nidades do Centro O bstétrico e Pronto Socorro A dulto, consideradas portas de entrada das mulheres em situação de violência neste serviço. A composição do grupo foi feita segundo os critérios: pertencimento ao quadro funcional e à equipe envolvida na assistência direta à mulher em situação de violência, totalizando seis técnicos de enfer magem, um auxiliar de enfermagem, três enfer meiras e dois médicos.

Para a seleção dos sujeitos foi realizado um sorteio com elaboração de uma relação de participantes. A pós esse momento, mediante convite ao primeiro sorteado e sua aceitação em participar do estudo, foi apresentado o termo de consentimento livre eesclarecido. 0 fechamento amostral foi definido pela saturação teórica a partir da convergência dos achados ao objetivo proposto no estudo(8). $\mathrm{N}$ a seqüência foi realizada a produção dos dados, no período entre abril e maio de 2008. Para manutenção do sigilo foi utilizado um código com letra E (entrevistado) e número.

Para a produção dos dados foi utilizada como técnica de coleta a vinheta e a entrevista semiestruturada. A vinheta consiste em uma descrição curta e compacta de uma situação ou um breve evento, real ou fictício, na qual os respondentes são solicitados a reagir. É estruturada visando extrair informações sobre percepções, para chamar a atenção, passar uma mensagem, produzir sensações e 
detectar comportamentos, atitudes, opiniões e conhecimentos dos sujeitos acerca do fenômeno investigado(9); no estudo em tela, a assistência a muIher es em situação de violência. A entrevista semiestruturada foi composta por oito questões, a qual foi aplicada de forma concomitante à vinheta, possibilitando complementação das técnicas, uma vez que as informações da primeira se integravam às da segunda.

As infor mações obtidas for am transcritas para posterior análise temática, que constituiu-se de três etapas: ordenação, classificação dos dados e análise final ${ }^{(10)}$. Foram identificadas as idéias centrais e aspectos rel evantes acerca da assistência às mulheres em situação de violência, no intuito de construir categorias empíricas. Para análise final, foi articulado o material estruturado ao referencial teórico do objeto de estudo, visando à identificação do conteúdo subjacente ao manifestado, na tentativa de responder às questões da pesquisa com base no objetivo.

\section{RESULTADOSE DISCUSSÕES}

Ante a interpretação dos dados, emergiram duas categorias: o diálogo como instrumento facilitador para a identificação da violência e encaminhamentos das mulheres e a complexidade do fenômeno e suas implicações na assistência.

\section{0 diálogo como instrumento facilitador para a identificação da violência e encaminhamentos das mulheres}

A visibilidade da violência contra as mulheres, bem como 0 aumento da demanda de casos desta natureza aos serviços de saúde, vem exigindo, de forma crescente, conhecimento e preparo dos profissionais de saúde, com vistas ao al cance de uma assistência resolutiva. D entre os requisitos conhecimento e preparo, os dados desta investigação apontaram para a relevância da relação dialógica entre os envolvidos, instrumento fundamental para identificação da violência e encaminhamentos das mulheres a serviços de apoio.

As informações elucidaram a necessidade do diálogo, no intuito de estabelecer vínculo por meio de uma escuta sensível e atenta como forma de conhecer a história de cada mulher assistida. A partir daí a identificação de situações de violência contra as mulheres passa a ser uma possibilidade.
Sublinha-se a preocupação de alguns profissionais em disponibilizar uma sala reservada, a fim de que a mulher sinta-se segura e à vontade para falar sobre si. E ntretanto, quando o diálogo não se efetiva, os profissionais al egaram dificuldades em identificar a violência, sendo as marcas corporais possíveis sinalizadores desta ag ressão.

Quando a coisa salta aos ol hos, como hematomas, arranhaduras, escoriações, queimaduras, facilita a identificação, mas têm muitas mulher es que sofrem violência que não identifico, passa desapercebido (E 08).

Os sujeitos do estudo acusaram como fundamental perceber a vontade ou não da mulher expressar a situação a que foi exposta, ou ocultá-la. É a partir da confirmação que o profissional poderá desenvolver ações que venham ao encontro das necessidades da usuária. $\mathrm{N}$ esse sentido, percebe-se a importância do diálogo, com o intuito de criar vínculo de confiança com a mulher.

T êm pacientes que contam que caíram, mas quena verdade foram empurradas pelo marido. E las negam a violência no momento quevocêsuspeita da história. Aí respei tamos a paciente, só identificamos com o aval dela (E 12).

Existem muitas razões - emocionais, sociais, econômicas, dentre outras - pelas quais, tanto a mulher na situação de violência quanto o ag ressor, tentam dissimular e ocultar a situação de violência. Há a possibilidade dessa mulher sentir vergonha, culpa e medo de falar abertamente, porque co-habita com esta violência ${ }^{(11)}$.

Tais sentimentos podem ter raízes na posição ocupada pela mulher no lar e dos papéis por ela desempenhados nesse ambiente, tais como o de mãe, esposa e dona-de-casa ${ }^{(12)}$. Essa concepção de muIher, no prisma das relações familiares, conduz a responsabilizá-la pela estabilidade do lar. D essa forma, ocultar a violência é condição básica para preservação de um ambiente doméstico suportável.

Nesta direção, a omissão, negação ou distorção do acontecimento, implica na naturalização da violência e afastamento dos profissionais de saúde das mulheres que sofrem esse tipo de agressão(13).

0 despreparo para identificar casos de violência contra as mulheres é evidenciado nas falas dos profissionais quando enfatizam a necessidade 
de capacitação profissional para a qualificação das ações em saúde nesta esfera.

Como a gente não é preparada, a maneira mais fácil éfazer de conta quenão existe, encaminhar para o psicólogo e ele resolve [ ...] aqui no serviço viu a paciente só uma vez, ela conta quecaiu de bicicleta e eu acredito (E 04).

$\mathrm{N}$ ão mesinto preparada, porque, não temos essepreparo. $\mathrm{N}$ ão tive nenhum tipo de capacitação, sabemos 0 básico (E 11).

Corrobora-se com estudo que ressalta a importância do preparo técnico e emocional do profissional para identificar as possíveis situações de violência contra as mulheres, recomendando a escuta sensível e um acolhimento adequado e resolutivo, bem como a formação de equipes multiprofissionais, que possibilitem implementação de programas de atendimento às mulheres nesta situação(14).

A dificuldade da identificação da violência e encaminhamento da mulher foi, também, atribuída à forma rápida que a assistência é realizada, 0 que impede o estabelecimento de diálogo. Os profissionais atribuem isto à complexidade e natureza do trabalho do pronto socorro principalmente, quando são priorizados casos em que há risco de vida. N este cenário os esforços concentram-se na repar ação de casos agudos, havendo uma lacuna no que diz respeito à prevenção e reabilitação da muIher. Reitera-se assim, uma assistência racional e intervencionista, sinônimo de instrumentalização(15).

No pronto socorro a relação é muito pouca, é muito paciente, não tem diálogo, é tudo mecanizado, faz a medicação enão conversa com a paciente, falta ter mais diálogo! (E 04).

R ealmente não se preocupa em saber 0 que aconteceu com elas antes de chegarem. É dada medicação para dor, curativo esó. N o pronto socor ro é assim, claro que não é cor reto, mas é assim que ocor re (E 03 ).

No setor de emergência hospitalar, a falta de atenção dos profissionais aos casos de violência é recorrente, sendo quea assistência está voltada para a queixa imediata que os pacientes apresentam no momento. U m fator que talvez contribua para isso é a alta demanda de pacientes no serviço, o que dificulta a oferta de atendimento articulado. Além disso, a assistência nesse serviço é voltada à lesão causada pelo trauma e não inclui um olhar à violência, pois esta não é considerada um problema de saúde, e muitas vezes, não é identificada como causa do trauma ${ }^{(16)}$

A política pública de saúde recomenda o uso de serviços de apoio como meios de enfrentamento à violência, na tentativa de buscar a reestruturação moral, psíquica e social da mulher (2). N esse sentido, quando questionados quanto ao conhecimento de serviços de apoio para encaminhamento das muIheres em situação de violência, as referências apontadas pelos profissionais dizem respeito à $D$ el egacia de Polícia para M ulher e serviço municipal de apoio psicossocial às vítimas de violência. Relatam que fazem as primeiras orientações e encaminham as mulher es para esses serviços, mas desconhecem seu funcionamento e não sabem quais as ações que são desencadeadas. D a mesma forma, com os serviços de apoio, não formalizam um diálogo, nem um fluxo de atendimento.

F iz emos o primeiro atendimento, depois perdemos essa mulher. $\mathrm{N}$ ão temos a contra referência. É feito atendimento e encaminhamos para serviço de psicologia, infectol ogia, mas não soubemos mais dela; passa o cuidado pra outro serviço e não retorna a informação (E 08).

N o hospital faz emos a nossa parte, mas não tudo. Chamamos psicól oga, mas não é tudo. P orque depois que sai daqui como fica? E las saem e não sabemos o que acontece, se procuraram ajuda nos outros serviços (E 09).

Semelhante a inquietação dos profissionais deste estudo, enfermeiras de U nidades Básicas de Saúde do município de Porto Alegre, Rio G rande do Sul, ressaltam o enfrentamento às situações de violência como um trabalho difícil, complexo e que não depende apenas das iniciativas do setor saúde. Algumas profissionais referiram frustração pessoal com a falta de resolubilidade da rede de apoio, aliados à falta de recursos materiais e humanos ${ }^{(17)}$.

A lgumas profissionais deste estudo alegaram que tentam minimizar a falta de resolução no que tange aos encaminhamentos, defendendo o estímu10 à independência e autonomia das mulheres como forma de prevenir situações violentas em seu cotidiano. D efendem, desta forma, o empoderamento feminino como possibilidade de superação das relações de opressão de seu cotidiano. 
D evemos trabalhar com as mulheres a independência, falar sobreisto com elas. M uitas a cabam se submetendo e se sujeitando à violência, porque não têm uma profissão nem como se livrar dos agressores (E 06).

Pesquisa realizada no município de São Paulo em um conjunto de serviços de assistência aos casos de violência contra mul her es aponta dados que vão ao encontro dos achados desse estudo. Ao classificar vocações assistenciais: a policial, a jurídica, a psicossocial e as orientações básicas; nesta última, incluíam-se os profissionais de saúde, com uma assistência enfocada na orientação e educação das mulheres. T ais profissionais enfatizaram a importância da participação da mulher na solução de seus problemas, no sentido de fortal ecer a emancipação e independência feminina, mostrando ainda, esses como princípios centrais nas suas práticas de saú$\mathrm{de}^{(18)}$.

\section{A complexidade do fenômeno e suas implicações para a assistência}

Q uando questionados sobre sua compreensão a respeito da violência contra as mulheres, os profissionais trouxeram na discussão o entendimento de ser um fenômeno complexo e grave. D efiniram a violência como agressões e atos físicos, sexuais, psicológicas, emocionais; que lembram humil hação, intimidação, desrespeito e inferioridade das mulheres.

Violência contra a mulher é toda aquela agressão de desrespeito, tanto físico, quanto moral, psicológico, que pode acontecer tanto na rua como em casa (E 02).

É um ato muito grave, é todo equalquer ato que possa desrespeitar, humilhar, não somentefísico, mas também o emocional (E 07).

Tal concepção pode demonstrar 0 entendimento dos profissionais quanto à magnitude do problema, vindo ao encontro da definição da Convenção de Belém do Pará, a qual reconhece a violência, também, como um problema de saúde pública, pois afeta a integridade física e a saúde mental das mulher es ${ }^{(1)}$. Percebe-se, na compressão dos profissionais, que a mulher poderá estar suscetível a estas agressões não somente no âmbito privado, como também em sua vida social pública.

Convergindo com esses achados, a compreensão da violência e a vitimização da mulher são caracterizados por médicos e enfermeiros de uma mater nidade pública de R ibeirão P reto, São Paulo, como um problema sério e importante na sociedade. A complexidade do fenômeno é percebida pelo grupo pesquisado e reconhecida em comportamentos nocivos praticados contra a mulher ${ }^{(15)}$.

D estaca-se, ante essa percepção, que o profissional de saúde envolvido com a assistência à muIher que sofre violência tem sentimentos aflorados, pelo impacto que a situação carrega em seu bojo. Os relatados pelos profissionais deste estudo estão associados à indignação, revolta, raiva, pena, dentre outros. Percebe-se que a violência cometida contra a mulher apresenta-se como um fenômeno difícil e penoso não somente para a usuária do serviço, mas também aos profissionais que a assistem.

Sinto muita raiva do agressor erevolta. $N$ ão se sabese acolhe, se bota no colo. É uma mistura de coisas, aparece eu, como mulher (E 08).

0 sentimento despertado nos profissionais evidencia envolvimento emocional com a mulher ag redida. E sta capacidade de se envolver e interessar-se pela outra pessoa parece expressar a noção de responsabilização sentida pelos profissionais. As falas permeiam também a empatia que a situação desperta, principalmente em profissionais do sexo feminino, mobilizando-as a pensar em em sua condição de mulher. A o mesmo tempo essa identificação parece possibilitar um ol har mais solidário às mulheres, implicando em uma assistência acoIhedora e humanizada.

E u como mul her, como mãe, como esposa, fico bastante sensibilizada com isso (E 10).

Sinto revolta, procuro mecolocar no lugar da paciente $N$ inguém gosta, ninguém quer (E 11 ).

As mulheres em situação de violência não apresentam perfil muito diferente das mulheres que não sofrem violência dentro de uma mesma sociedade. $\mathrm{N}$ ão existem diferenças significativas entre essas e as outras mulheres de sua cultura ou classe social , embora as apreciações pessoais do valor próprio e competências diminuam em situações de violência(19).

E m contra ponto, discursos de al guns profissionais preservam o não envolvimento, evidenciando o receio em se envolver com a situação e/ ou com a mulher em situação de violência. Entende- 
se que tal postura possa ser uma estratégia para 0 profissional se proteger diante de uma situação que também 0 agride. A o mesmo tempo, pode se pensar que a visão de mundo racional, o modelo de assistência inter vencionista e tecnicista possam ser facilitadores de comportamentos dessa nature$\mathrm{za}^{(6,11)}$.

$N$ ós médicos, não temos que nos colocar no lugar da paciente, não tem que fazer isso, porque senão acaba sentindo raiva [ ...] Porque senão, não vai poder ajudar essa paciente (E 12).

Profissionais de saúde de duas equipes do Programa de Saúde da Mulher do município do Rio de Janeiro, sendo uma delas referência para 0 atendimento às situações de violência, apontam inquietações em relação a comportamentos como este. $\mathrm{N}$ a unidade não-referência os profissionais dizem preferir não se envolver, por anteverem os obstáculos e não poderem gar antir à mulher a resolução do seu problema. Já, na unidade referência, os profissionais acolhem tal demanda. Entretanto, constatam que, embora com a tentativa de realizar um atendimento qualificado, muitas vezes, não conseguem impedir que a mulher continue vivenciando as situações de violência ${ }^{(20)}$.

Considerando a complexidade da temática, bem como a crescente exigência dos profissionais em oferecer uma atenção qual ificada às usuárias que sofrem violência, os sujeitos deste estudo demonstraram preocupação por não terem vivenciado discussões com tal abordagem, tanto na academia como em cursos de nível médio. Expressam que a lacuna desta contribuição na for mação são limitações que implicam na qualidade da assistência articulada às mulheres.

$\mathrm{N}$ a formação não ouvi falar quase nada. Só quando existia al gum caso de suspeita deviolência era abordada muito superficialmente (E 08 ).

$\mathrm{N}$ a minha formação não ouvi falar praticamentenada (E 10).

N esta mesma esteira, no que diz respeito ao conhecimento da legislação e da política que envolve o tema, os profissionais de saúde refer em não conhecer, ou sabem muito pouco sobre 0 assunto. A pontam a Lei M aria da Penha como instrumento legal de enfrentamento à violência e como possibilidade de oferecer à mulher orientações pautadas em referenciais afeitos aos direitos humanos e cidadania; embora seu conhecimento restrito acerca deste dispositivo possa limitar sua atuação.

Profissionais, em geral, saem das univer sidades sem condições de assumir a responsabilidade de trabal har em um serviço público, em defesa da vida dos usuários, ou com capacidade para escutar o que o paciente diz e o que não diz; ver o que está por trás de uma queda ou de um assal to(19).

N este estudo, os profissionais destacaram a necessidade de capacitação para qualificação e humanização de sua assistência, como forma de suprir lacunas de sua formação. É premente perceber a violência como problema social que afeta profundamente a saúde das mulheres e reconhecer seu papel específico como parte de uma rede de suporte social ${ }^{(3)}$. É imprescindível que os serviços assumam uma postura de responsabilização e implementem uma estrutura de assistência voltada à identificação e acompanhamento terapêutico das situações de violência ${ }^{(7)}$.

E videncia-se assim, a responsabilidade dos órgãos formadores no preparo de futuros profissionais, de compreender essa questão no âmbito da saúde e reconhecer seu papel social na identificação e assistência articulada nas situações de violência contra as mulheres.

\section{CONSIDERAÇÕES FINAIS}

Esta investigação realizada em um hospital de ensino, no qual as pesquisadoras desenvolvem atividades teórico-práticas, possibilitou perceber importante receptividade dos sujeitos envolvidos, tendo em vista a pertinência do tema estudado. $\mathrm{Na}$ medida em que evidenciou limitações na assistência às mulheres em situação de violência, representadas pela fal ta de diál ogo e conhecimento para identificar a violência e fazer encaminhamentos necessários, demonstrou a urgência em abordar a questão de forma sistematizada em processos de educação permanente no nível institucional.

D a mesma for ma, a mobilização emocional dos profissionais, ante situações a que estão expostos, tanto no centro obstétrico como no pronto socorro da instituição cenário do estudo, direciona para reflexões relevantes, que denunciam certa violência também aos profissionais dos serviços, tendo em vista a posição de meros expectadores de situações que poderiam resolver se houvesse maior conhecimento e existência de uma rede integrada de 
apoio às mulheres em situação de violência no município.

0 estudo aponta, de forma contunde também, a urgência das instituições e dos órgãos formadores de profissionais da saúde compreenderem a violência contra as mulheres como uma questão de saúde pública. N esta ótica, portanto, deve ter seu conteúdo ministrado formalmente na academia e em cursos que preparam para a assistência ao ser humano, como forma de ir ao encontro da atual Política Nacional de A tenção I ntegral à Saúde da M ulher.

Pode-se afirmar o impacto positivo deste estudo, na medida em que tem mobilizado o Observatório da Violência da instituição para esta direção, chamando para a discussão os atores envolvidos com essa questão, no sentido de construir coletivamente uma rede assistencial que permita às mulheres uma assistência qualificada em nível municipal.

\section{REFERÊNCIAS}

10 rganização dos E stados A mericanos. Convenção I nteramericana para P revenir, P unir e E rradicar a Violência Contra a M ulher "Convenção de B elém do Pará" (1994) [ Internet]. São Paulo: Biblioteca Virtual de Direitos H umanos, U niversidade de São Paulo; 1994 [ citado 2009 jun 02]. D isponível em: http:// www. direitoshumanos.usp.br/ index.php/ D ireitos-da-M uIher/ convencao-interamericana-para-prevenir-punire-erradicar-a-violencia-contra-a-mulher-qconvencaode-belem-do-paraq-1994.html.

2 M inistério da Saúde (BR ), Secretaria de A tenção à Saúde, D epartamento de A ções Programáticas Estratégicas. Política Nacional de A tenção Integral à Saúde da M ulher: princípios e diretrizes. Brasília (DF ); 2007.

3 Schraiber LB, D'Oliveira AFPL. 0 que devem saber os profissionais de saúde para promover os direitos e a saúde das mulheres em situação de violência doméstica: projeto gênero, violência e direitos humanos: novas questões para o campo da saúde. $2^{2}$ ed. São PauIo: F undação F ord, CRE M E SP ; 2003.

4 Cruz ICF. A sexualidade, a saúde reprodutiva e a violência contra a mulher negra: aspectos de interesse para assistência de enfermagem. R ev E sc Enferm U SP. 2004;38(4):448-57.

5 Porto JRR, L uz A M H. M atizes da violência contra a mulher: conhecendo o fenômeno. Rev $\mathrm{G}$ aúcha $\mathrm{E}$ nferm. 2004;25(2):207-18.
6 Guzmán YER, Tyrrell MAR. Construyendo un lenguaje incomun en mujeres víctimas de violencia conjugal. Esc A nna N ery Rev E nferm. 2008;12(4):67984.

7 Riquinho DL, Correia SG 0 papel dos profissionais de saúde em casos de violência doméstica: um relato de experiência. R ev G aúcha Enferm. 2006;27(2):30110.

8 Fontanella BJB, Ricas J, T urato ER. A mostragem por saturação em pesquisas qualitativas em saúde: contribuições teóricas. Cad Saúde Pública. 2008;24 (1):17-27.

9 Polit DF, Hungler BP. F undamentos da pesquisa em enfermagem: métodos, avaliação e utilização. Porto Alegre: Artmed; 2004.

10 M inayo M CS. 0 desafio do conhecimento: pesquisa qualitativa em saúde. 10ª ed. São Paulo: H ucitec; 2007.

11 Vieira LJES, Pordeus AMJ, Ferreira RC, M oreira D P, M aia PB, Saviolli KC. F atores de risco para violência contra a mulher no contexto doméstico e coletivo. Saúde Soc. 2008;17(3):113-25.

12 Signori M , M adureira VSF. A violência contra a muIher na perspectiva de policias militares: espaço para a promoção da saúde. Acta Sci, H ealth Sci. 2007; 29(1):7-17.

13 Corrêa M SM , Lopes RLM, Diniz N M F. Reflexões sobre o cuidar de mulheres que sofrem violência conjugal em uma perspectiva heideggeriana do mundo da técnica. Rev E sc Enferm U SP. 2001;35(3):223-9.

$14 \mathrm{Freitas} F \mathrm{~F}$, L una $M \mathrm{G}, \mathrm{D} y \mathrm{tz} J \mathrm{LG}$. A tendimento à mulher vítima de violência sexual no Programa $\mathrm{Vi}$ oleta, D istrito Federal. Comun Ciênc Saúde. 2007; 18(3):185-95.

15 Lettiere A, N akano M AS, Rodrigues DT. Violência contra a mulher: a visibilidade do problema para um grupo de profissionais de saúde. Rev Esc Enferm U SP. 2008;42(3):467-73.

16 L eal SM C, Lopes M J M . A violência como objeto da assistência em um hospital de trauma: 0 "olhar" da enfermagem. Ciênc Saúde Colet. 2005;10(2):419-31.

17 Rückert TR, Lima M AS, M arques GQ, Garlet ER, Pereira W AP, A costa AM . A ssistência em unidades básicas de saúde às vítimas de violência na concepção de enfermeir as. Ciênc Cuid Saúde. 2008;7(2):1806. 
$18 \mathrm{~K}$ iss LB, Schraiber LB, D 'Oliveira AFPL. Possibilidades de uma rede inter setorial de atendimento a muIheres em situação de violência. Interface Comun Saúde E duc. 2007;11(23):485-501.

19 M eneghel SN, Camargo M , Fasolo LR, M attiello DA, Silva RCR, Santos T CB, et al. M ulheres cuidando de mulheres: um estudo sobre a Casa de A poio Viva
M aria, Porto Alegre, Rio G rande do Sul, Brasil. Cad Saúde Pública. 2000;16(3):747-57.

20 Borsoi T S, Brandão E R, Caval canti M LT. A ções para o enfrentamento da violência contra a mulher em duas unidades de atenção primária à saúde no município do Rio de J aneiro. Interface Comun Saúde E duc. 2009;13(28):165-74.
Endereço da autora / Dirección del autor / Author's address:

Letícia Becker Vieira

Rua Reinoldo Schimidt, 33, Centro

96900-000, Sobradinho, RS

E-mail: lebvieira@hotmail.com
Recebido em: 07/ 07/ 2009

A provado em: 08/ 12/ 2009 